\title{
O TRABALHO E A FORMAÇÃO HUMANA À LUZ DA ONTOLOGIA DO SER SOCIAL
}

\section{EL TRABAJO Y LA FORMACIÓN HUMANA A LA LUZ DE LA ONTOLOGÍA DEL SER SOCIAL}

\section{WORK AND HUMAN FORMATION IN THE LIGHT OF THE ONTOLOGY OF BEING SOCIAL}

\author{
VAZ, Marta Rosani Taras \\ martarosanni@hotmail.com \\ UEPG - Universidade Estadual de Ponta Grossa \\ https://orcid.org/0000-0002-6944-0341 \\ MASSON, Gisele \\ gimasson@uol.com.br \\ UEPG - Universidade Estadual de Ponta Grossa \\ https://orcid.org/0000-0002-9799-5950
}

\begin{abstract}
Resumo Este artigo é resultado de uma pesquisa bibliográfica cujo objetivo é apresentar uma análise sobre as categorias trabalho e educação e demonstrar como elas têm se desenvolvido na particularidade histórica da sociedade capitalista. Essa discussão parte dos pressupostos teóricos de Marx e de Lukács. Consideramos também a contribuição de outros autores tais como Tonet $(2005,2006,2011)$ e Lessa (1996, 2012a, 2012b). Há uma relação intrínseca entre o trabalho e a formação humana e, decorrente disso, as possibilidades de desenvolvimento das múltiplas potencialidades humanas são inviabilizadas enquanto houver exploração do trabalho. Contudo, com a possibilidade histórica de transformação social radical, podemos considerar a contribuição da educação no processo de constituição e consolidação da emancipação humana.
\end{abstract}

Palavras-chave: Formação Humana. Ontologia do Ser Social. Trabalho.

Resumen Este artículo es el resultado de una investigación bibliográfica cuyo objetivo es presentar un análisis de las categorías trabajo y educación y demostrar cómo se ha desarrollado en la particularidad histórica de la sociedad capitalista. Esta discusión parte de los supuestos teóricos de Marx y Lukács. También consideramos la contribución de otros autores como Tonet $(2005,2006,2011)$ y Lessa $(1996$, 2012a, 2012b). Existe una relación intrínseca entre el trabajo y la formación humana y, como resultado, las posibilidades de desarrollo de las múltiples potencialidades humanas se hacen inviables mientras existe la explotación del trabajo. Sin embargo, con la posibilidad histórica de una transformación social radical, podemos considerar la contribución de la educación al proceso de constitución y consolidación de la emancipación humana.

Palabras clave: Formación Humana. La ontología del Ser Social. Trabajo. 


\section{Atos de Pesquisa em Educação - ISSN 1809-0354 \\ Blumenau, v.14, n.2, p.310-331, mai./ago. 2019 \\ DOI: http://dx.doi.org/10.7867/1809-0354.2019v14n2p310-331}

Abstract: This article is the result of a bibliographic research whose aim is to present an analysis on the categories work and education and demonstrate how they have developed in the historical particularity of capitalist society. This discussion starts from the theoretical assumptions of Marx and Lukács. We also considered the contribution of other authors such as Tonet $(2005,2006,2011)$ and Lessa (1996, $2012 a, 2012 b)$. There is an intrinsic relationship between work and human formation and, as a result, the possibilities of developing the multiple human potentialities are impossible while there is work exploited. However, with the historical possibility of radical social transformation, we can consider the contribution of education in the process of constitution and consolidation of human emancipation.

Keywords: Human Formation. Ontology of Social Being. Work.

\section{INTRODUÇÃO}

Este artigo é resultado de uma pesquisa bibliográfica que buscou problematizar como se dá a relação entre os complexos do trabalho e da educação, do ponto de vista da sua gênese e do seu desenvolvimento histórico. Assim, o objetivo é apresentar uma análise sobre as categorias trabalho e educação e demonstrar como elas têm se desenvolvido na particularidade histórica da sociedade capitalista. Para tanto, as reflexões realizadas neste texto partem dos pressupostos teóricos de Marx e Lukács, uma vez que compreendemos a educação como uma práxis social, originária da relação do homem com a natureza, pela mediação do trabalho. Assim, a partir da Ontologia do Ser Social, entendemos que o processo educativo/formativo se origina do processo de trabalho, tendo "uma dependência ontológica, autonomia relativa e relação recíproca". (TONET, 2011, p. 139).

Desse modo, o trabalho vem se constituindo como uma mediação fundamental, pois é a partir dele que produzimos aquilo que é necessário para a reprodução da vida humana. A educação, por sua vez, enquanto um "processo de aquisição de conhecimentos, habilidades, comportamentos, valores, etc. que permitam ao indivíduo tornar-se apto a participar conscientemente (mesmo que essa consciência seja limitada) da vida social" (TONET, 2011, p. 139), torna-se uma parte do complexo social essencial para a reprodução do gênero humano.

Assim como o trabalho assume características específicas que variam de acordo com um determinado momento histórico e se modifica conforme as necessidades dos diferentes modos de produção e formas de sociabilidade, o processo educacional se molda aos interesses dominantes de cada tempo. 
Nesse sentido, as discussões da categoria trabalho e da categoria educação devem vir acompanhadas tanto de uma análise histórico-filosófica, a fim de que possamos conceituá-los de forma genérica, buscando evidenciar os seus elementos essenciais, quanto de uma análise das características dessas categorias em uma determinada forma de sociabilidade específica, com o intuito de explicitarmos as mudanças que ocorreram em relação à sua gênese histórica.

Com base na Ontologia do Ser Social de Lukács, compreendemos o trabalho como intercâmbio do homem com a natureza, o qual contribui para o desenvolvimento do processo educativo/formativo enquanto uma práxis social, já que esta é fundamental para a socialização de conhecimentos e habilidades, elaborados no processo de trabalho e imprescindíveis para o desenvolvimento do próprio trabalho.

Porém, na sociedade capitalista, o trabalho é, predominantemente, assalariado, ou seja, é necessário que o homem venda sua força de trabalho em troca de um salário para que, com este, possa realizar a compra de mercadorias que satisfaçam as suas necessidades, que são históricas e variam do "estômago a imaginação"1. No mesmo sentido, dada a sua dependência ontológica com o trabalho, o processo educativo/formativo assume características específicas do momento histórico capitalista, como a formação fragmentada, técnica, profissionalizante e mercantilizada.

Na seção seguinte, abordaremos o trabalho em geral, a partir de uma análise histórico-filosófica, e elucidaremos seus principais momentos, com o intuito sinalizar sua relação ontológica com a educação.

\section{PROCESSO DE TRABALHO COMO FUNDANTE DA EDUCAÇÃO}

\footnotetext{
${ }^{1}$ Marx e Engels (2007) consideram que os homens precisam ter condições de viver para fazer história, desde as condições mais simples, ligadas às necessidades biológicas, como beber, comer, dormir, entre outras, e podem provir do "estômago ou da imaginação". (MARX, 2013, p.113). Para Marx e Engels (2007, p.33), "o primeiro fato histórico é, pois, a produção dos meios para a satisfação dessas necessidades, a produção da própria vida material." A produção, que se dá a partir do trabalho, possibilita que "a satisfação dessa primeira necessidade, a ação de satisfazê-la e o instrumento já adquirido conduzem a novas necessidades." (MARX; ENGELS, 2007, p.33).
} 


\title{
Atos de Pesquisa em Educação - ISSN 1809-0354 \\ Blumenau, v.14, n.2, p.310-331, mai./ago. 2019 \\ DOI: http://dx.doi.org/10.7867/1809-0354.2019v14n2p310-331
}

Quando pensamos em trabalho, remetemos ao trabalhador que vende sua força de trabalho em troca de um salário. Esse processo de mercantilização é uma característica fundamental do momento histórico capitalista. Marx (2013) alerta que a forma capitalista do trabalho, a qual se manifesta a partir da compra e venda de força de trabalho humano, não o representa em sua plenitude, ou seja, é possível outra relação do homem com o trabalho que extrapola a relação de exploração existente na sociedade capitalista. Para o referido autor,

\begin{abstract}
O trabalho é, antes de tudo, um processo entre homem e a natureza, processo este em que o homem, por sua própria ação, medeia, regula e controla seu metabolismo com a natureza. Ele se confronta com a matéria natural como uma potência natural. A fim de se apropriar da matéria natural de uma forma útil para sua própria vida, ele põe em movimento as forças naturais pertencentes a sua corporeidade: seus braços e pernas, cabeça e mãos. Agindo sobre a natureza externa e modificando-a por meio desse movimento, ele modifica, ao mesmo tempo, sua própria natureza. (MARX, 2013, p.255).
\end{abstract}

Dessa forma, quando nos referimos ao trabalho que realiza a mediação entre o homem e a natureza, estamos atribuindo a ele o sentido ontológico e concreto, ou seja, a sua característica essencial - originária. A teorização em torno do trabalho, na perspectiva da Ontologia do Ser Social, advém de um estudo aprofundado realizado pelo filósofo marxista Lukács, no entanto, é em Marx que a concepção ontológica do ser social já apresenta os seus fundamentos filosóficos.

Quando Marx (2013, p. 255) enuncia que "o trabalho é, antes de tudo um processo entre homem e natureza”, ele está se referindo ao trabalho que está intimamente ligado ao desenvolvimento do ser social, distinguindo-o da sua forma histórica assalariada. A categoria trabalho tem centralidade na teoria marxista, uma vez que ela está presente, tanto na constituição dos pressupostos filosóficos, quanto na da crítica da economia política, por ser ele o fundamento do ser social e, também, fonte de mais-valia.

Marx e Engels indicaram o papel do trabalho no desenvolvimento do ser social, partindo da premissa de que "o primeiro pressuposto de toda a história humana é, naturalmente, a existência de indivíduos vivos". (MARX; ENGELS, 2007, p.87). As premissas que surgem a partir dessa constatação se referem aos indivíduos reais e às suas condições reais de existência, portanto, possuem bases materiais e não idealizadas ou abstraídas da imaginação. (MARX; ENGELS, 2007). 


\section{Atos de Pesquisa em Educação - ISSN 1809-0354 \\ Blumenau, v.14, n.2, p.310-331, mai./ago. 2019 \\ DOI: http://dx.doi.org/10.7867/1809-0354.2019v14n2p310-331}

Os seres humanos, de acordo com os autores, "começam a se distinguir dos animais tão logo começam a produzir seus meios de vida. [...] Ao produzirem seus meios de vida, os homens produzem, indiretamente, sua própria vida material." (MARX; ENGELS, 2007, p.87).

Para Marx, o processo de trabalho é composto por três elementos fundamentais, sendo, em primeiro lugar, a atividade orientada a um fim, uma vez que "além do esforço dos órgãos que trabalham, a atividade laboral exige a vontade orientada a um fim" (MARX, 2013, p. 256). Em segundo lugar, o seu objeto é preexistente, quando "o trabalho apenas separa de sua conexão imediata com a totalidade da terra" ou matéria prima, nesse caso "o próprio objeto de trabalho já é, por assim dizer, filtrado por um trabalho anterior". (MARX, 2013, p. 256). Por último, os seus meios, que são "uma coisa ou um complexo de coisas que o trabalhador interpõe entre si e o objeto de trabalho e que lhe serve de guia de sua atividade sobre seu objeto". (MARX, 2013, p. 256). Desse modo,

No processo de trabalho, portanto, a atividade do homem, com ajuda dos meios de trabalho, opera uma transformação do objeto do trabalho segundo uma finalidade concebida desde $\mathrm{o}$ início. $O$ processo se distingue no produto. Seu produto é um valor de uso, um material natural adaptado às necessidades humanas por meio da modificação de sua forma. O trabalho se incorporou a seu objeto. Ele está objetivado, e o objeto está trabalhado. O que do lado do trabalhador aparecia sob a forma do movimento, agora se manifesta, do lado do produto, como qualidade imóvel, na forma do ser. Ele fiou, e o produto é um fio. (MARX, 2013, p. 258).

O produto do trabalho é trabalho objetivado, ou seja, a ação do homem sobre o objeto de trabalho transforma a sua natureza, no entanto, na sua totalidade, como mediação entre homem e natureza ou sujeito e objeto, esse é um processo complexo. Lukács empreendeu estudos que explicam a complexidade do trabalho no processo de constituição do ser social, resultando na obra Para uma Ontologia do Ser Social.

Para o autor, "a essência do trabalho humano consiste no fato de que, em primeiro lugar, ele nasce em meio à luta pela existência e, em segundo lugar, todos os seus estágios são produtos de sua autoatividade." (LUKÁCS, 2013, p. 43). Para ele, o trabalho "é, essencialmente, uma inter-relação entre homem (sociedade) e natureza, tanto inorgânica (ferramenta, matéria-prima, objeto de trabalho, etc.) como orgânica, mas antes de tudo assinala a transição, no homem que trabalha do ser 


\section{Atos de Pesquisa em Educação - ISSN 1809-0354 \\ Blumenau, v.14, n.2, p.310-331, mai./ago. 2019 \\ DOI: http://dx.doi.org/10.7867/1809-0354.2019v14n2p310-331}

meramente biológico ao ser social." (LUKÁCS, 2013, p. 44). Essa compreensão lukácsiana é uma reafirmação da compreensão marxiana acerca do trabalho humano, como é possível observar nas palavras de Marx (2013, p.120):

Como criador de valores de uso, como trabalho útil, o trabalho é, assim, uma condição de existência do homem, independente de todas as formas sociais, eterna necessidade natural de mediação do metabolismo entre homem e natureza e, portanto, da vida humana.

Marx enfatizou que o que difere a atividade animal do trabalho humano é que, no homem, a atividade já estava idealizada e orientada a um fim, enquanto que, nos animais, a satisfação das necessidades é resultado de uma atividade instintiva com níveis de consciência muito elementares. Lukács (2013) chama a atenção ao conteúdo ontológico essencial do trabalho humano, que é constituído marcadamente pelo caráter cognitivo. Em Lukács, esse caráter cognitivo é chamado de teleologia, a qual pressupõe a prévia ideação (antecipação do resultado do trabalho na consciência). Desse modo,

[...] o primeiro impulso para o pôr teleológico provém da vontade de satisfazer uma necessidade. No entanto, esse é um traço comum à vida tanto humana como animal. Os caminhos começam a divergir quando entre necessidade e satisfação se insere o trabalho, o pôr teleológico. E nesse mesmo fato, que implica o primeiro impulso para o trabalho, se evidencia a sua constituição marcadamente cognitiva, uma vez que é indubitavelmente uma vitória do comportamento consciente sobre a mera espontaneidade do instinto biológico quando entre a necessidade e a satisfação imediata seja introduzido o trabalho como mediação. (LUKÁCS, 2013, p.78).

Primeiramente, toda atividade orientada a um fim, que está previamente idealizada no ser antes de sua execução, parte de uma necessidade, ou seja, a própria prévia-ideação, assim como a teleologia, já é resultado de uma relação material do homem com a natureza e fruto das necessidades humanas. Dessa forma, "não é a consciência que determina a vida, mas a vida que determina a consciência." (MARX; ENGELS, 2007, p. 94). Contudo, para Lukács, toda teleologia, para fazer parte do processo de trabalho, precisa de um "pôr", ou seja, sair da consciência e ser objetivada. Desse modo,

Antes de qualquer outra coisa, a característica real decisiva da teleologia, isto é, o fato de que ela só pode adquirir realidade enquanto pôr, recebe um fundamento simples, óbvio, real: nem é preciso repetir Marx para entender que qualquer trabalho seria impossível se ele não fosse precedido de tal 


\section{Atos de Pesquisa em Educação - ISSN 1809-0354 \\ Blumenau, v.14, n.2, p.310-331, mai./ago. 2019 \\ DOI: http://dx.doi.org/10.7867/1809-0354.2019v14n2p310-331}

pôr, que determina o processo em todas as suas etapas. (LUKÁCS, 2013, p. 51).

Nesse sentido, com o ato do pôr teleológico, é atribuído à consciência um papel ativo de transformação do real, fazendo com que o caráter meramente especulativo e idealista seja substituído por um caráter transformador, tanto do sujeito (ser social), quanto do objeto (natureza). Essa relação da consciência subjetiva, que é fruto de uma realidade objetiva, demonstra que a compreensão marxiana da relação sujeito versus objeto não recai num materialismo puro e mecanicista como o de Feuerbach ${ }^{2}$ ou num dualismo metodológico.

Nesse sentido, Lukács (2013, p. 48) considera que,

[...] conceber teleologicamente a natureza e a história implica não somente que ambas possuem um caráter de finalidade, que estão voltadas para um fim, mas também que sua existência, seu movimento, no conjunto e nos detalhes devem ter um autor consciente. (LUKÁCS, 2013, p.48).

De acordo com Labica (2003, p.66), "o subjetivo é corolário do objetivo, ele leva diretamente à consideração do 'aspecto ativo'. Sua desconsideração deixa qualquer materialismo desarmado diante do idealismo." Desse modo, ao negar o papel do pensamento e da subjetividade, Feuerbach "só consegue restabelecer o antigo confronto direto dualista do objeto e do sujeito", por isso, "a constatação crítica de Marx: pensar é contemplar." (LABICA, 2003, p.73). A décima primeira tese sobre Feuerbach deixa clara a pretensão do materialismo histórico-dialético de intervir na realidade: "Os filósofos apenas interpretaram o mundo de diferentes maneiras; o que importa é transformá-lo." (MARX, 2007, p. 535). Sendo assim, na relação sujeito-objeto, a posição teleológica do trabalho expressa, justamente, o caráter ativo dos homens, o trabalho como "modelo de todas as práxis".

Marx já havia demonstrado o caráter histórico e transformador do ser social, dentre outros textos, na obra O Dezoito Brumário de Louis Bonaparte, na qual enuncia: "os homens fazem sua própria história, mas não a fazem segundo a sua livre vontade; não a fazem sob circunstâncias de sua escolha e sim sob aquelas com

\footnotetext{
${ }^{2}$ No caso de Feuerbach, a realidade só é concebida por meio da intuição ou da sensibilidade puramente objetiva, ou seja, o autor atribui ênfase à objetividade do real, desconsiderando o caráter ativo dos sujeitos. Essa é a falha principal de todos os materialismos anteriores ao materialismo histórico-dialético. Nas Teses Sobre Feuerbach, Marx (2007) aponta para o mérito do Idealismo, opondo-se ao Materialismo mecanicista, ao desenvolver o lado "ativo" da consciência, embora de maneira abstrata e idealista.
} 


\section{Atos de Pesquisa em Educação - ISSN 1809-0354 \\ Blumenau, v.14, n.2, p.310-331, mai./ago. 2019 \\ DOI: http://dx.doi.org/10.7867/1809-0354.2019v14n2p310-331}

que se defrontam diretamente, legadas e transmitidas pelo passado". (MARX, 2006, p. 15).

Para Lukács, a transformação do objeto, a partir do trabalho, expressa uma teleologia posta, ou seja, o pensamento se torna material novamente. Isso porque a teleologia já é uma expressão da materialidade. No entanto, quando posta, demonstra o papel da consciência na transformação do real. Tanto para Marx, quanto para Lukács, só existe teleologia a partir do trabalho, pois não existe um fim em si mesmo nos objetos e na própria história, ao contrário do que acreditam as filosofias metafísicas. Nesse sentido, Lukács (2013, p. 54) explica que "no ser-em-si da pedra não há nenhuma intenção, e até nem sequer um indício de possibilidade de ser usada como faca ou como machado". Dessa forma, não existe teleologia no objeto ou na natureza, a teleologia é própria do ser humano, mas só tem caráter transformador se ela for posta em movimento.

É válido ressaltar que o trabalho possibilita uma relação entre a teleologia e a causalidade (relações de causa e efeito na natureza), sendo que a causalidade pode ser espontânea, não-posta e posta. (LUKÁCS, 2013). Para Lukács (2013, p. 48), a causalidade é "um princípio de automovimento que repousa sobre si próprio", a causalidade em si, ou seja, inteiramente natural é espontânea; por sua vez, a causalidade não-posta é restrita à esfera cognitiva do ser, ou seja, do conhecimento que o ser tem sobre as relações causais da natureza e que, a partir do pôr teleológico do trabalho, torna-se causalidade posta, natureza modificada. Considerando isso, a teleologia, em sua essência, só pode funcionar enquanto posta, pois "é no trabalho, nos seus atos que transformam a causalidade espontânea em causalidade posta”. (LUKÁCS, 2013, p. 90).

Podemos, novamente, interpretar um dos momentos em que Marx (2013) discorre sobre o papel transformador do trabalho: "o que do lado do trabalhador aparecia sob a forma do movimento, agora se manifesta, do lado do produto, como qualidade imóvel, na forma do ser." (MARX, 2013, p.258). Sendo assim, a natureza ao lado do trabalhador está em forma de movimento, mas enquanto trabalho objetivado perde essa forma e se manifesta como valor de uso. Nesse sentido, a forma do movimento da natureza é a causalidade espontânea e o produto do trabalho, como qualidade imóvel, apresenta-se como causalidade posta. "Natureza e 


\section{Atos de Pesquisa em Educação - ISSN 1809-0354 \\ Blumenau, v.14, n.2, p.310-331, mai./ago. 2019 \\ DOI: http://dx.doi.org/10.7867/1809-0354.2019v14n2p310-331}

trabalho, meio e fim chegam, desse modo, a algo que é em si homogêneo: o processo de trabalho e, ao final, o produto do trabalho." (LUKÁCS, 2013, p.55). No entanto, a causalidade posta não tem o poder de alterar absolutamente a causalidade espontânea, pois essa apresenta determinados limites em função de suas características essenciais. Por exemplo, mesmo que determinada árvore seja transformada em determinada mobília, sua madeira sofrerá, ao longo do tempo, uma transformação da matéria.

O processo de transmutação da teleologia em causalidade posta é, segundo Lukács, o momento da objetivação. De acordo com Lessa (2012a), a partir de Lukács, a objetivação "articula a idealidade da teleologia com a materialidade do real sem que, por esta articulação, a teleologia e a causalidade percam suas respectivas essências, deixem de ser ontologicamente distintas." (LESSA, 2012a, p. 65). Nesse sentido, não só o objeto é subjetivado como também o sujeito é objetivado, uma vez que, no processo de objetivação, há uma exteriorização da individualidade, assim como uma transformação do sujeito em relação aos seus conhecimentos e habilidades. Para Lessa (2012a, p.125), “a objetivação corresponde ao momento de transformação teleologicamente orientada do real, e a exteriorização ao momento da ação do retorno da objetivação e do objetivado sobre o indivíduo agente". No entanto, além de refletir o retorno do trabalho objetivado sobre o sujeito, a exteriorização reflete as características subjetivas na transformação do objeto. Compreendemos, dessa forma, que no momento da exteriorização, há uma relação recíproca entre sujeito e objeto. Segundo Lessa (2012b, p. 39),

A exteriorização é esse momento do trabalho pelo qual a subjetividade, com seus conhecimentos e habilidades, é confrontada com a objetividade a ela externa, à causalidade e, por meio deste confronto, pode não apenas verificar a validade do que conhece e de suas habilidades, como também pode desenvolver novos conhecimentos e habilidades que não possuía anteriormente.

Embora façamos um exercício de abstração para compreender o processo de trabalho em seus momentos mais fundamentais, devemos ter claro que o trabalho faz parte da totalidade social e todos os seus momentos devem ser apreendidos em termos da coletividade social. Sendo assim, o próprio ser social, na visão lukácsiana, é uma totalidade de seres, resultado do processo de socialização e generalização. 


\section{Atos de Pesquisa em Educação - ISSN 1809-0354 \\ Blumenau, v.14, n.2, p.310-331, mai./ago. 2019 \\ DOI: http://dx.doi.org/10.7867/1809-0354.2019v14n2p310-331}

Dessa maneira, podemos considerar que o caráter essencial da educação, no seu sentido amplo, surge do processo de generalização do trabalho. Isso porque, do trabalho mais simples e primitivo, ao trabalho mais complexo e moderno, foi fundamental a transmissão de todos os conhecimentos adquiridos pelo homem na realização do trabalho.

As descobertas e invenções, as criações de valores de uso, foram generalizadas entre os indivíduos, membros da sociedade, dando origem a novos processos de trabalho, complexificando os indivíduos e a sociedade, desenvolvendo as forças produtivas e modificando as relações de produção. Em síntese, promovendo o desenvolvimento do gênero humano. (LESSA, 1996). Isso quer dizer que a generalização dos conhecimentos para o conjunto da sociedade indica que o ser social é um indivíduo isolado, mas também um indivíduo genérico ${ }^{3}$, uma vez que tem a capacidade de transmitir e aprender novos conhecimentos e habilidades. Lukács (2013, p.86), explicita que:

Na medida em que as experiências de um trabalho concreto são utilizadas em outro, ocorre gradativamente sua - relativa - autonomia, ou seja, a fixação generalizadora de determinadas observações que já não se referem de modo exclusivo e direto a um único procedimento, mas, ao contrário, adquirem certa generalização como observações de eventos da natureza em geral. São essas generalizações que formam os germes das futuras ciências, cujos inícios, no caso da geometria e da aritmética, se perdem em um passado remoto.

Quando Lukács enfatiza o trabalho no processo de desenvolvimento do ser social, não está diminuindo a importância de outras mediações que fazem parte do complexo social, como a linguagem e a educação. Porém, compreende que o trabalho é o modelo de todas as práxis sociais e que a linguagem e a educação são mediações que surgem, ontologicamente, como uma necessidade do próprio trabalho, no curso do seu desenvolvimento histórico. Por isso, Lukács (2013, p.83) afirma que

[...] o trabalho é um processo entre a atividade humana e natureza: seus atos estão orientados para a transformação de objetos naturais em valores de uso. Nas formas ulteriores e mais desenvolvidas da práxis social, destaca-se em primeira plano a ação sobre outros homens, cujo objetivo é,

\footnotetext{
${ }^{3}$ Tonet (2005, p.39), a partir de Marx, afirma que “[...] o homem é um ser genérico e universal, pois o devir do indivíduo não se dá apenas, e nem principalmente, como um desdobramento de leis genéricas, mas implica, sobretudo, a apropriação das objetivações que se tornam patrimônio do gênero humano."
} 


\section{Atos de Pesquisa em Educação - ISSN 1809-0354 \\ Blumenau, v.14, n.2, p.310-331, mai./ago. 2019 \\ DOI: http://dx.doi.org/10.7867/1809-0354.2019v14n2p310-331}

em última instância - mas somente em última instância-, uma mediação para a produção de valores de uso.

O trabalho é, portanto, produtor de valores de uso, porém, a produção cada vez mais complexa implica em um determinado nível de socialização de conhecimentos e habilidades e de organização do processo educacional. Sabemos que a educação escolar cumpre essa função, assim, o professor exerce o papel de medição entre os homens do conhecimento necessário para a reprodução do ser social.

A reprodução do ser social exige, portanto, determinado nível de formação humana, a qual se dá a partir de um processo educativo/formativo. Vale destacar que a formação humana necessária para a reprodução do ser social na atualidade é fragmentada e unilateral. De acordo com Tonet (2006), o conceito de formação humana integral está ligado ao acesso aos bens materiais e espirituais, por parte dos indivíduos, promovendo a aproximação dos homens com o gênero humano. Desse modo, segundo o autor, não é possível falarmos em processos educativos que realizem a formação humana integral sem alcançarmos a emancipação humana, por meio de uma transformação social radical.

Formação humana e trabalho se relacionam, já que um se torna condição fundamental para o desenvolvimento do outro, mesmo em seus níveis mais elevados. Para Tonet (2011), a educação se relaciona com o trabalho, estabelecendo uma dependência ontológica, uma autonomia relativa e uma determinação recíproca. O autor explica essa questão, da seguinte forma:

Dependência ontológica no sentido de que a educação tem a sua matriz na forma como os homens se organizam para transformar a natureza. Autonomia no sentido de que ela se constitui como uma esfera e uma função específicas, portanto diferentes do trabalho, e que, justamente para cumprir essa função própria, tem que organizar-se de maneira independente dele. E determinação recíproca, no sentido de que há uma relação de influência mútua entre a educação e todos os outros momentos da totalidade social - trabalho, política, direito, arte, religião, ciência, filosofia, etc. (TONET, 2011, p. 141).

Consideramos que o processo de trabalho, especialmente em suas formas mais desenvolvidas, implica níveis de conhecimentos cada vez mais elevados e que devem ser transmitidos para a humanidade, por meio da generalização desses saberes. 


\section{Atos de Pesquisa em Educação - ISSN 1809-0354 \\ Blumenau, v.14, n.2, p.310-331, mai./ago. 2019 \\ DOI: http://dx.doi.org/10.7867/1809-0354.2019v14n2p310-331}

De acordo com Ramos (2010, p.98),

Ontologicamente, o ser humano precisa aprender a produzir sua própria existência, o que nos leva a concluir que a produção do homem é, ao mesmo tempo, a formação do homem; isto é, um processo educativo. A origem da educação coincide, então, com a origem do próprio homem. Mas esse aprendizado se modifica juntamente com as mudanças pelas quais passam de trabalho, de produção da existência, de sorte que a relação entre o trabalho e a educação é tanto ontológica quanto histórica.

Para Tonet (2006), é a partir da apropriação do patrimônio material e espiritual da humanidade que o indivíduo singular se constitui enquanto membro do gênero humano e tem as condições reais para o desenvolvimento da sua formação humana integral. No caso das sociedades primitivas, antes do surgimento das classes sociais, a formação humana dos indivíduos perpassava por todos os membros de uma comunidade. No entanto, devido ao baixo nível de desenvolvimento social e cultural, assim como do baixo desenvolvimento das forças produtivas, a formação humana apresentava limites (TONET, 2006).

No caso da sociabilidade capitalista, é a centralidade do trabalho abstrato que permite entender a subordinação da formação cultural/espiritual/humana aos imperativos da produção da riqueza e, portanto a impossibilidade de uma autêntica formação humana integral. (TONET, 2006, p.3).

Dessa forma, é possível compreender que, com o advento da sociedade capitalista, dois fenômenos acontecem concomitantemente. Por um lado, o alto grau de desenvolvimento das forças produtivas eleva a produção da riqueza material e espiritual; de outro lado, a divisão de classes (donos dos meios de produção versus trabalhadores) faz com que grande parte da população mundial não tenha acesso à riqueza produzida, excluindo os indivíduos das condições de desenvolvimento humano e social. (TONET, 2006).

Portanto, se a formação humana ou formação integral dos homens só é possível a partir da apropriação, por parte de todos os indivíduos, do patrimônio acumulado historicamente pela humanidade - espiritual, cultural, social -, é necessário romper com a desigualdade social originária da divisão de classe e exploração do trabalho humano. Para Tonet (2006, p.5), "uma formação realmente integral supõe a humanidade constituída sob a forma de uma autêntica comunidade humana, e esta pressupõe, necessariamente, a supressão do capital." 


\title{
Atos de Pesquisa em Educação - ISSN 1809-0354 \\ Blumenau, v.14, n.2, p.310-331, mai./ago. 2019 \\ DOI: http://dx.doi.org/10.7867/1809-0354.2019v14n2p310-331
}

Entendida desse modo, formação humana em sua plenitude só é possível com a superação da subordinação do trabalho ao capital e a partir da instauração do que Marx chamou de "trabalho associado" ou "associação livre dos produtores livres", ou seja, só será possível a partir de uma reorganização das relações de produção e da revolução das forças produtivas.

$\mathrm{Na}$ seção seguinte, evidenciamos as principais características do trabalho neste modo de produção e discutimos a educação na condição de reprodução da formação do trabalhador moderno.

\section{TRABALHO ASSALARIADO E A FORMAÇÃO DO TRABALHADOR}

$\mathrm{Na}$ forma capitalista de sociabilidade, o trabalho se manifesta, predominantemente, sob a forma abstrata de trabalho assalariado, portanto, na forma de mercadoria. Na citação seguinte, extraído da obra Trabalho assalariado e Capital, Marx (1975) se refere ao trabalho abstrato na sociedade capitalista, da seguinte forma:

\begin{abstract}
A força de trabalho, portanto, é uma mercadoria que seu possuidor, o assalariado, vende ao capital. E para que a vende? Para viver.

Mas a manifestação da força de trabalho, o trabalho, é a atividade vital própria do operário, a manifestação pessoal da sua vida. E é esta atividade vital que ele vende a um terceiro para assegurar os meios de subsistência necessários. Por isso, a sua atividade vital não é para ele mais do que um meio para poder existir. Ele trabalha para viver. Nem sequer considera o trabalho como uma parte da sua vida; para ele, é muito mais um sacrifício da sua vida (MARX, 1975, p.21).
\end{abstract}

A abstração do trabalho no capitalismo faz com que outras atividades que não realizam o intercâmbio material entre homem e natureza se tornem trabalho pela simples razão de serem assalariadas. Dessa forma, atividades relativas ao processo educativo, exercidas por sujeitos que recebem em troca determinada quantia de dinheiro, pela prestação de seus serviços, são assalariadas.

De modo geral, com o desenvolvimento do capitalismo, sob as ruínas da sociedade feudal - no caso europeu - e sob a forma politicamente orientada ${ }^{4}$ - no

\footnotetext{
${ }^{4}$ Para Faoro (1979), o desenvolvimento do capitalismo brasileiro aconteceu de maneira peculiar, se comparado aos países europeus, uma vez que, ao invés de se originar de uma revolução das estruturas materiais e sociais, instaurou-se sob uma forma politicamente orientada, buscando
} 


\section{Atos de Pesquisa em Educação - ISSN 1809-0354 \\ Blumenau, v.14, n.2, p.310-331, mai./ago. 2019 \\ DOI: http://dx.doi.org/10.7867/1809-0354.2019v14n2p310-331}

caso brasileiro -, o antagonismo de classes não deixou de existir, porém, simplificouse, pois "a sociedade inteira vai-se dividindo cada vez mais em dois grandes campos inimigos, em duas grandes classes diretamente opostas entre si: burguesia e proletariado". (MARX; ENGELS, 2007, p.46). A história não esconde quão grande foi o papel revolucionário da burguesia, sem falar que "a burguesia não pode existir sem revolucionar continuamente os instrumentos de produção e, por conseguinte, as relações de produção, portanto, todo o conjunto das relações sociais". (MARX; ENGELS, 2007, p. 48).

Nesse sentido, a contínua revolução das relações sociais de produção demanda a transformação do processo de exploração do trabalho humano, a partir das necessidades desse novo modo de produção. Uma das contribuições legadas por Marx, a partir da obra O Capital, é justamente compreender a forma que o trabalho assume no capitalismo.

Para o autor, o processo de produção e acumulação capitalista modifica os significados do processo de trabalho, tendo como fim último, não a produção de valores de uso, embora ela não deixe de existir, mas a produção de valores de troca, com o intuito de gerar valor e valorizar incessantemente o capital. Para Lessa (2012a, p. 28),

O trabalho abstrato é a redução da capacidade produtiva humana a uma mercadoria, a força de trabalho, cujo preço é o salário. Todas as atividades humanas assalariadas são trabalho abstrato. O trabalho enquanto categoria fundante é o complexo que cumpre a função social de realizar o intercâmbio material do homem com a natureza, é o conjunto de relações sociais encarregado da reprodução da base material da sociedade.

$\mathrm{Na}$ sociedade capitalista, a força de trabalho é uma mercadoria como outra qualquer, uma vez que é negociada no mercado a preço do salário. Marx (2013, p. 270) destaca que "o valor de uso da força de trabalho, o próprio trabalho, pertence tão pouco a seu vendedor quanto o valor de uso do óleo pertence ao comerciante que o vendeu." O trabalho assalariado é, para o capitalista, fundamental para a produção de mais-valor, pois "assim como qualquer mercadoria é possuidora do valor de uso e de valor, seu processo de produção tem de ser a unidade de processo de trabalho e processo de formação de valor." (MARX, 2013, 263).

conciliar o novo modo de produção com os interesses locais, baseados no poder patrimonialista, estamental e burocrático. 


\section{Atos de Pesquisa em Educação - ISSN 1809-0354 \\ Blumenau, v.14, n.2, p.310-331, mai./ago. 2019 \\ DOI: http://dx.doi.org/10.7867/1809-0354.2019v14n2p310-331}

O capitalista (dono dos meios de produção) quer, além da produção de valores de uso, produzir valor de troca, substância de valor. Para Marx (2013, p. 263), “aqui, os valores de uso só são produzidos porque e na medida em que são o substrato material, os suportes do valor de troca." Na produção da mercadoria, não interessa ao capitalista qual é o valor de uso dela, mas sim, o seu valor de troca, já que "quer produzir uma mercadoria cujo valor seja maior do que a soma do valor das mercadorias requeridas para a sua produção, os meios de produção e a força de trabalho, para cuja compra ele adiantou seu dinheiro no mercado." (MARX, 2013, p. 263). No entanto, o capitalista quer mais, quer "produzir não só um valor de uso, mas uma mercadoria; não só valor de uso, mas valor, e não só valor, mas também mais-valor." (MARX, 2013, p. 263).

É válido ressaltar que nem todo trabalho assalariado é formador de maisvalor, pois Marx denominou de trabalho produtivo aquele que gera mais-valor e trabalho improdutivo aquele que não está diretamente ligado à sua produção. É importante sublinhar que essa diferenciação diz respeito, unicamente, ao processo de trabalho abstrato. Diante dessa questão, Marx (2013, p. 578) afirma que "a produção capitalista não é apenas produção de mercadoria, mas essencialmente, produção de mais-valor", por isso, "só é produtivo o trabalhador que produz maisvalor para o capitalista ou serve à autovalorização do capital." Nesse sentido, o que o trabalhador produz não é para si, mas para o capitalista, ao trabalhador resta vender a força de trabalho em troca de um salário que possibilite a reprodução de sua existência.

É necessário, então, considerar, a partir de Marx, que produtivo e improdutivo se referem ao trabalho do ponto de vista do capital. Desse modo, os trabalhos improdutivos são tão fundamentais na realização de capital quanto os produtivos. Sobre isso, no Capítulo VI inédito de O Capital, Marx (2004) acentua que:

Com o desenvolvimento da subordinação real do trabalho ao capital ou do modo de produção especificamente capitalista não é o operário individual que se converte no agente (Funktionar. Al) real do processo de trabalho no seu conjunto mas sim uma capacidade de trabalho socialmente combinada; e, como as diversas capacidades de trabalho que cooperam e formam a máquina produtiva total participam de maneira muito diferente no processo imediato de formação de mercadorias, ou melhor, neste caso, de produtos um trabalha mais com as mãos, outros mais com a cabeça, este como diretor (manager. Ing.), engenheiro (engineer. Ing.), técnico etc., aquele como capataz (overlooker. Ing.), aquele outro como operário manual ou até 


\section{Atos de Pesquisa em Educação - ISSN 1809-0354 \\ Blumenau, v.14, n.2, p.310-331, mai./ago. 2019 \\ DOI: http://dx.doi.org/10.7867/1809-0354.2019v14n2p310-331}

como simples servente -, temos que são cada vez em maior número as funções da capacidade de trabalho incluídas no conceito imediato de trabalho produtivo, diretamente explorados pelo capital e subordinados em geral ao seu processo de valorização e de produção. (MARX, 2004, p.110).

Compreendemos que a necessidade do capital de gerar mais-valor, implica a contínua revolução do modo de produção e da exploração da força de trabalho, bem como dos processos sociais que o envolvem, determinando, em última instância, diversos setores, como a educação por exemplo.

Desde a sua forma originária, o trabalho pressupõe a existência de determinadas habilidades e conhecimentos humanos. Sendo assim, o trabalho assalariado também necessita de uma determinada formação educacional.

Se olharmos, historicamente, para o processo de massificação da escolarização dos trabalhadores, percebemos que a ampliação do acesso à escola básica não esteve ligada, predominantemente, à finalidade de possibilitar as condições para que o trabalhador se apropriar do patrimônio histórico cultural da humanidade para o desenvolvimento da formação humana, mas teve o intuito de preparar a força de trabalho, de acordo com as exigências do mercado de trabalho, em diferentes momentos históricos.

Analisando a divisão técnica do trabalho, o autor Adam Smith, a partir de sua visão liberal, defendia o "espírito comercial", porém, reconhecia que tal espírito gerava certo "inconveniente". Para o autor, "a visão das pessoas se restringe, e 'quando toda a atenção de uma pessoa se concentra no décimo sétimo componente de um alfinete ou no oitavo componente de um botão', a pessoa se torna obtusa." (SMITH, 1996, p.33). Nesse sentido, o liberal Smith defende a popularização do ensino, porém, esse ensino deve ser concedido de forma limitada e controlada. Para Marx (2013), "como modo de evitar a degeneração completa da massa do povo decorrente da divisão do trabalho, A. Smith recomenda o ensino popular, a cargo do Estado, embora em doses cautelosamente homeopáticas." (MARX, 2013, p. 436).

Ao recomendar o ensino em doses homeopáticas para a classe trabalhadora, Smith acreditava que, além de tornar as pessoas menos obtusas, tornaria o trabalhador mais apto a cumprir seu trabalho técnico na indústria, tornando-se um trabalhador moderno. A concepção smithiana de educação veio se complementar à concepção liberal de John Locke, o qual compreendia que a educação era destinada 


\section{Atos de Pesquisa em Educação - ISSN 1809-0354 \\ Blumenau, v.14, n.2, p.310-331, mai./ago. 2019 \\ DOI: http://dx.doi.org/10.7867/1809-0354.2019v14n2p310-331}

somente àqueles que dispunham de tempo e propriedade. A defesa do ensino popular, a cargo do Estado, é resultado, em certa medida, das lutas da classe trabalhadora vinculadas à pauta pela diminuição da jornada de trabalho, inclusive do trabalho infantil e, contraditoriamente, a ampliação do ensino popular responde a uma necessidade do próprio desenvolvimento capitalista, que pretende, de um lado, formar força de trabalho adequada aos interesses capitalistas e, de outro, difundir, por meio de um ensino popular, a ideologia burguesa.

A acentuação da desigualdade social contribuiu para dar novos sentidos para a educação escolar que deixou, pelo menos no plano ideológico, apenas um espaço para a formação do trabalhador, para ser concebida como uma possibilidade de ascensão econômico-social.

Para Gentili (2013), com a expansão dos sistemas escolares, no contexto capitalista mais amplo, a partir da segunda metade do século XIX, difundiu-se a promessa da escola como entidade integradora. Tanto a classe dominante, quanto a classe trabalhadora consideravam, nesse período, que a escola funcionava como um mecanismo de integração social em seu sentido amplo.

A ênfase atribuída à escola como instituição de integração econômica e social marcou o século XX e coincidiu com o que Hobsbawm (1995) chamou de Era de Ouro do desenvolvimento capitalista. O suposto impacto dessa escola integradora, com potencial econômico, foi tão grande que, nos anos de 1960 e 1970, foi desenvolvida uma teoria específica que se preocupou em discutir tais questões: a teoria do capital humano. (GENTILI, 2013).

De acordo com Frigotto (2013), a elaboração do conceito de capital humano, por Theodoro Schultz, no final da década de 1950 e início da década de 1960, vinculava a formação do trabalhador ao desenvolvimento econômico-social, tanto individual como de uma nação. O conceito de capital humano estava vinculado à tese do pleno emprego, difundindo

a ideologia que o investimento no capital humano permitiria aos países subdesenvolvidos desenvolverem-se, e aos indivíduos a garantia de melhores empregos, maior produtividade e, por essa via, mobilidade e ascensão social." (FRIGOTTO, 2013, p.15). 


\section{Atos de Pesquisa em Educação - ISSN 1809-0354 \\ Blumenau, v.14, n.2, p.310-331, mai./ago. 2019 \\ DOI: http://dx.doi.org/10.7867/1809-0354.2019v14n2p310-331}

No entanto, a teoria capital humano demonstrou, com o passar do tempo, sua fragilidade e seu caráter ideológico, pois se percebeu que nada do que se postulava nessa concepção se efetivou.

O final do século XX foi marcado pela crise do trabalho e, concomitantemente, pela globalização tecnológica. Segundo Gentili (2013), se por um lado o alto nível de desenvolvimento tecnológico possibilitou a globalização e o deslocamento de investimentos produtivos por todo o mundo; por outro lado, aumentou drasticamente a intensidade de capital morto e diminuiu, consequentemente, a força de trabalho. "[...] com essas armas o capital vem desmobilizando e minguando o poder sindical que se vê forçado a negociar conquistas por uma garantia mínima de emprego." (GENTILI, 2013, p.42).

Percebeu-se que, com a crise do trabalho, a concepção acerca da formação do trabalhador, como integradora econômica e social, perdeu a sua força ideológica. Porém, "a desintegração da promessa integradora não tem suposto a negação da contribuição econômica da escolaridade, e sim uma transformação substantiva em seu sentido." (GENTILI, 2013, p.81). Dessa forma, o papel econômico da formação perde o caráter coletivo e ganha caráter privado, ou seja, reconhece-se que não é possível a formação profissional possibilitar a ascensão econômica e social para toda a sociedade, mas sim, possibilita o desenvolvimento de habilidades e capacidades individuais. Segundo Gentili (2013, p.81), "a desintegração da promessa integradora deixará lugar à difusão de uma nova promessa, agora sim, de caráter estritamente privado: a promessa da empregabilidade."

De acordo com Gentili (2004, p.52),

'empregabilidade' é o eufemismo da desigualdade estrutural que caracteriza o mercado de trabalho e que sintetiza a incapacidade - também estrutural da educação de cumprir sua promessa integradora numa sociedade democrática.

A promessa da empregabilidade acompanha os pressupostos de flexibilização do trabalho e de formação profissional permanente. Nesse sentido, ela não supera o suposto caráter de integração econômico-social da teoria do capital humano, uma vez que continua atribuindo aos processos educativos e formativos, portanto, ao próprio trabalhador, a responsabilidade de superar as suas mazelas econômicas e sociais, responsabilizando-o pelo desemprego, pela miséria, pela 


\section{Atos de Pesquisa em Educação - ISSN 1809-0354 \\ Blumenau, v.14, n.2, p.310-331, mai./ago. 2019 \\ DOI: http://dx.doi.org/10.7867/1809-0354.2019v14n2p310-331}

desigualdade, entre outras condições a que precisa se submeter na sociedade capitalista.

Percebemos, desse modo, que devido à conexão ontológica ineliminável entre trabalho e educação, essa última é produzida conforme as necessidades históricas do trabalho e, portanto, das relações sociais de produção. Dada a principal característica do trabalho na sociedade capitalista, de exploração do homem pelo homem, por meio da produção de mais-valor, compreende-se que todo o sistema educacional se volta, predominantemente, à reprodução da estrutura social vigente. Todavia, não deixam de ser considerados projetos e ações que se delineiam na direção oposta, a exemplo da perspectiva que tem como finalidade contribuir para a emancipação humana.

\section{CONSIDERAÇÕES FINAIS}

A partir da problematização de como se dá a relação entre os complexos do trabalho e da educação, do ponto de vista da sua gênese e do seu desenvolvimento histórico o objetivo deste estudo foi apresentar uma análise sobre as categorias trabalho e educação e demonstrar como elas têm se desenvolvido na particularidade histórica da sociedade capitalista. Com base no que foi discutido, consideramos que os complexos sociais do trabalho e da educação possuem uma intrínseca relação, sendo que o trabalho se constitui, essencialmente, como o intercâmbio do homem com a natureza. Nessa perspectiva, a atividade do professor ou a educação, no sentido amplo, não é trabalho, mas uma práxis social que possui uma "dependência ontológica, uma autonomia relativa e uma relação recíproca" (TONET, 2011, p. 139.) com o complexo do trabalho.

Nesse sentido, a essência da educação consiste em informar e influenciar os homens a desenvolverem determinados conhecimentos e habilidades necessários para a efetivação do trabalho. Compreende-se que toda sociedade necessita que seus indivíduos se apropriem de determinada quantidade e qualidade de conhecimentos, habilidades, comportamentos. (LUKÁCS, 2013).

Para que o processo de trabalho se realize, ou seja, para que ocorra o pôr teleológico do trabalho, nas formas mais superiores de organização do trabalho, 


\section{Atos de Pesquisa em Educação - ISSN 1809-0354 \\ Blumenau, v.14, n.2, p.310-331, mai./ago. 2019 \\ DOI: http://dx.doi.org/10.7867/1809-0354.2019v14n2p310-331}

outros pores teleológicos mediados são necessários, como a educação. Tais pores não buscam a modificação da natureza objetiva, mas têm como finalidade a modificação da natureza subjetiva dos homens, como no caso de um homem que precisa convencer outro grupo de homens a executar o por teleológico do trabalho. (LUKÁCS, 2013).

Ao longo da história da humanidade, os homens estiveram organizados a partir de determinada divisão social do trabalho, enquanto alguns caçavam, outros cozinhavam e outros exerciam outras práxis sociais. Com o desenvolvimento das sociedades, novas atividades foram surgindo, algumas mais específicas e outras menos, algumas mais diretas na modificação da natureza e outras não. Desse modo, a atividade docente ocupa uma função específica na divisão social do trabalho, sendo ela a responsável por mediar a relação do homem com os conhecimentos e habilidades historicamente produzidos pela humanidade, constituindo-se como um por sócio-teleológico.

No seu aspecto geral, compreendemos que a educação cumpre o papel de possibilitar que os homens se apropriem dos conhecimentos, habilidades, valores e comportamentos que constituem o ser social, ocupando uma importante função na reprodução do ser social. (TONET, 2011).

Portanto, é possível afirmar que o processo educativo/formativo é uma práxis social fundada pelo trabalho. Pelo exposto, consideramos que só é possível compreender a educação na sua essência se analisarmos essa categoria na sua relação com o trabalho, situados numa totalidade social. Tendo em vista a sociabilidade capitalista e as relações sociais de produção originadas da relação capital e trabalho, é possível afirmar que a função social dos processos educativos está voltada, predominantemente, para a manutenção da exploração do trabalho humano, de tipo assalariado.

Desse modo, à luz da Ontologia do Ser Social, é possível afirmar que está completamente inviabilizada a possibilidade de uma formação educacional que vise a formação humana integral, dada as condições a que se submete o trabalho humano na atual organização social. Contudo, essa limitação historicamente determinada não pode nos desarmar perante as possibilidades históricas de superação da sociedade capitalista, já que a formação educacional, na sua relação 
Atos de Pesquisa em Educação - ISSN 1809-0354

Blumenau, v.14, n.2, p.310-331, mai./ago. 2019

DOI: http://dx.doi.org/10.7867/1809-0354.2019v14n2p310-331

de reciprocidade com o trabalho, pode também contribuir para a construção da emancipação humana.

\section{MARTA ROSANI TARAS VAZ}

Doutoranda em Educação na Universidade Estadual de Ponta Grossa (UEPG). Mestre em Educação pela Universidade Estadual de Ponta Grossa (UEPG). Membro do Grupo de Pesquisa Capital, Trabalho, Estado, Educação e Políticas Educacionais (GPCATE).

\section{GISELE MASSON}

Doutora em Educação pela Universidade Federal de Santa Catarina (UFSC). Mestre em Educação pela Universidade Estadual de Ponta Grossa (UEPG). Professora do Departamento de Educação e do Programa de Pós-Graduação em Educação da UEPG.

\section{REFERÊNCIAS}

FAORO, R. Os donos do Poder: formação do patronato político brasileiro. 5. ed. Porto Alegre: Globo, 1979.

FRIGOTTO, G. Apresentação. In: FRIGOTTO, G. (Org.). Educação e Crise do Trabalho. 12. ed. Petrópolis: Vozes, 2013.

GENTILI, P. Três teses sobre a relação trabalho e educação em tempos neoliberais. In: LOMBARDI, J. C; SAVIANI, D.; SANFELICE, J. C. (Orgs.). Capitalismo Trabalho e Educação. Campinas: Autores Associados, 2004.

Educar para o desemprego: a desintegração da promessa integradora. In: FRIGOTTO, G. (Org.). Educação e Crise do Trabalho. 12. ed. Petrópolis: Vozes, 2013.

HOBSBAWM, E. A Era dos Extemos: o breve século XX. São Paulo: Companhia das Letras, 1995.

LABICA, G. As "Teses sobre Feuerbach" de Karl Marx. Rio de Janeiro: Jorge Zahar Editor, 2003.

LESSA, S. A centralidade ontológica do trabalho em Lukács. Serviço Social e Sociedade, São Paulo, v. 52, p. 7-23, 1996.

$2012 a$

Mundo dos homens: trabalho e ser social. São Paulo: Instituto Lukács, 


\section{Atos de Pesquisa em Educação - ISSN 1809-0354 \\ Blumenau, v.14, n.2, p.310-331, mai./ago. 2019 \\ DOI: http://dx.doi.org/10.7867/1809-0354.2019v14n2p310-331}

. Para compreender a ontologia de Lukács. 3. ed. ljuí: Unijuí, 2012b.

LUKÁCS, G. Para uma ontologia do ser social II. São Paulo: Boitempo, 2013.

MARX, K. Trabalho Assalariado e Capital: Salário, preço e lucro. Porto: Publicações Escorpião, 1975.

. Capítulo VI: inédito de O Capital. 2. ed. São Paulo: Centauro, 2004.

. O Dezoito Brumário de Louis Bonaparte. São Paulo: Centauro, 2006.

Teses sobre Feuerbach. In: MARX, K.; ENGELS, F. A ideologia alemã: Crítica da mais recente filosofia alemã em seus representantes Feuerbach, B. Bauer e Stirner, e do socialismo alemão em seus diferentes profetas. São Paulo: Boitempo, 2007.

2013.

O capital: crítica da economia política. Livro. 1. São Paulo: Boitempo,

MARX, K.; ENGELS, F. A ideologia alemã: Crítica da mais recente filosofia alemã em seus representantes Feuerbach, B. Bauer e Stirner, e do socialismo alemão em seus diferentes profetas. São Paulo: Boitempo, 2007.

RAMOS, M. Trabalho, educação e correntes pedagógicas no Brasil: um estudo a partir da formação dos trabalhadores técnicos da saúde. Rio de Janeiro: Edufrj, 2010.

SMITH, A. A. Riqueza das Nações: investigações sobre sua natureza e suas causas. Coleção Os Pensadores. v.1. São Paulo: Nova Cultural, 1996.

TONET, I. Educação, cidadania e emancipação humana. ljuí: Unijuí, 2005. Disponível em:<http://ivotonet.xpg.uol.com.br/arquivos/EDUCACAO_CIDADANIA_E _EMANCIPACAO_HUMANA.pdf>. Acesso em: 28 jul. 2015.

. Educação e formação humana. Maceió: 2006. Disponível em: <http://ivotonet.xpg.uol.com.br/arquivos/EDUCACAO_E_FORMACAO_HUMANA.pdf >. Acesso em: 10 fev. 2015.

. Educação e Ontologia marxiana. Revista HISTEDBR On-line, Campinas, número especial, p. 135-145, 2011. 